\title{
A Multi-Systems Approach to Human Movement after ACL Reconstruction: The Musculoskeletal System
}

\author{
Daniel Larson, PT, DPT, ATC, SCS, CSCS ${ }^{1}$, Vien Vu, PT, DPT, SCS, CSCS², Brandon M Ness, PT, DPT, PhD, $\mathrm{SCS}^{3}$, \\ Elizabeth Wellsandt, PT, DPT, PhD, OCS ${ }^{4}$, Scot Morrison, PT, DPT, OCS, $\operatorname{CSCS}^{5}$ \\ ${ }^{1}$ Lawrence Memorial Hospital/OrthoKansas, ${ }^{2}$ Samaritan Athletic Medicine; Oregon State University Athletics Department, ${ }^{3}$ Doctor of Physical \\ Therapy Program, Tufts University School of Medicine, ${ }^{4}$ Division of Physical Therapy Education, University of Nebraska Medical Center; Department \\ of Orthopaedic Surgery and Rehabilitation, University of Nebraska Medical Center, 5 PhysioPraxis PLLC; Department of Neuroscience, Biomedicine \\ and Movement Sciences, University of Verona \\ Keywords: anterior cruciate ligament, anterior cruciate ligament reconstruction, musculoskeletal system, movement system, rehabilitation \\ https://doi.org/10.26603/001c.29456
}

\section{International Journal of Sports Physical Therapy}

Vol. 17, Issue 1, 2022

\begin{abstract}
Several negative adaptations to the musculoskeletal system occur following anterior cruciate ligament (ACL) injury and ACL reconstruction (ACLR) such as arthrogenic muscle inhibition, decreased lower extremity muscle size, strength, power, as well as alterations to bone and cartilage. These changes have been associated with worse functional outcomes, altered biomechanics, and increased risk for re-injury and post-traumatic osteoarthritis. After ACL injury and subsequent ACLR, examination and evaluation of the musculoskeletal system is paramount to guiding clinical decision making during the rehabilitation and the return to sport process. The lack of access many clinicians have to devices necessary for gold standard assessment of muscle capacities and force profiles is often perceived as a significant barrier to best practices. Fortunately, testing for deficits can be accomplished with methods available to the clinician without access to costly equipment or time-intensive procedures. Interventions to address musculoskeletal system deficits can be implemented with a periodized program. This allows for restoration of physical capacities by adequately developing and emphasizing physical qualities beginning with mobility and movement, and progressing to work capacity and neuromuscular re-education, strength, explosive strength, and elastic or reactive strength. Additional considerations to aid in addressing strength deficits will be discussed such as neuromuscular electrical stimulation, volume and intensity, eccentric training, training to failure, cross-education, and biomechanical considerations. The American Physical Therapy Association adopted a new vision statement in 2013 which supported further development of the profession's identity by promoting the movement system, yet validation of the movement system has remained a challenge. Application of a multi-physiologic systems approach may offer a unique understanding of the musculoskeletal system and its integration with other body systems after ACLR. The purpose of this clinical commentary is to highlight important musculoskeletal system considerations within a multi-physiologic system approach to human movement following ACLR.
\end{abstract}

\section{Level of Evidence}

5

\footnotetext{
a Correspondence:

Brandon Ness, PT, DPT, PhD

Doctor of Physical Therapy Program

Tufts University School of Medicine

136 Harrison Ave

Boston, MA, 02111

Email: Brandon.Ness@tufts.edu
} 


\section{INTRODUCTION}

The American Physical Therapy Association adopted a new vision statement in $2013^{1}$ which supported further development of the profession's identity by promoting 'the movement system as the foundation for optimizing movement to improve the health of society. 2 The movement system refers to the body's ability to generate and maintain movement through integration of all body systems and functions. ${ }^{3}$ Although efforts are currently ongoing, adoption and validation of the movement system has been somewhat challenging across physical therapist practice, education, and research, ${ }^{4,5}$ let alone in the context of specific clinical diagnoses including anterior cruciate ligament (ACL) injury. A framework for understanding movement development, motor control and skill acquisition may be better realized within the context of dynamical systems theory which aims to explain variability in human goal-directed movment. ${ }^{6}$ Dynamical systems theory is described as a multidisciplinary, systems-based approach to explain systems that change over time, and works to build understanding of a complex system through its individual component parts. ${ }^{6}$ Dynamical systems theory and the APTA movement system concept share a commonality, in that the interaction and integration of component systems contributes to the success of the system as a whole. Each physiologic system of an individual can be thought of as representing a component system necessary for efficient, goal-directed human movement. Therefore, the purpose of this clinical commentary is to highlight important musculoskeletal system considerations within a multi-physiologic system approach to human movement following ACL reconstruction (ACLR). Specifically, topics will be discussed related to 1) musculoskeletal adaptations after ACL injury and ACLR, 2) clinical examination and evaluation of musculoskeletal health after ACLR, and 3) musculoskeletal rehabilitation strategies to optimize human movement.

\section{MUSCULOSKELETAL SYSTEM ADAPTATIONS AFTER ACL INJURY AND ACL RECONSTRUCTION}

Many changes occur in the musculoskeletal system after ACL injury and ACLR. An important alteration occurring both after injury and surgery is loss of range of motion (ROM), which may impact functional activities that have task-dependent ROM needs in order for the task to be executed efficiently. In particular, incidence of knee extension loss greater than five degrees compared to the uninvolved limb has been reported to be as high as $25 \%$ at four weeks postoperatively in a sample of 229 patients. ${ }^{7}$ Twelve and five percent of patients may not have achieved equal ROM compared to the uninvolved side by six and 12 months, respectively. ${ }^{8}$ This is significant as it has been shown to be associated with post-operative complications such as arthrofibrosis, quadriceps inhibition, gait abnormalities, patellofemoral pain, altered patellofemoral and tibiofemoral arthrokinematics and articular cartilage contact pressures, and early onset osteoarthritis (OA). ${ }^{9,10}$ Further, extension loss is a common factor leading to revision surgeries. ${ }^{11}$ While flexion ROM loss does occur after injury and surgery, it does not tend to affect the knee as much as extension loss. However, a loss of 15 degrees of flexion is considered unsatisfactory for most patients, ${ }^{12}$ and any degree of long-term flexion loss may be considered suboptimal for those intending to return to activities involving running, cutting, and/or jumping. ${ }^{13,14}$

Two of the most documented changes after ACL injury and ACLR are reductions in size and strength of muscle groups around the knee. A recent meta-analysis reported that quadriceps cross-sectional area (CSA) and volume may be decreased in the ACLR limb compared to the contralateral limb. ${ }^{15}$ These negative quadriceps changes were evident when examined from 3 to 29 months post-surgery, indicating that they do not spontaneously resolve. Although all included studies reported negative effect sizes supporting this trend, only $36 \%$ of studies contained confidence intervals that did not cross zero, indicating other factors beyond muscle size likely contribute to the quadriceps strength deficits that are common in these patients. Other factors that can contribute to muscle strength include neural components (motor unit recruitment, recruitment thresholds, synchronization, firing frequency, intermuscular coordination, etc.), fiber type composition and pennation angle, fascicle length, and muscle fat content. ${ }^{16}$ Noehren et al. reported not only decreased quadriceps muscle volume, but also changes in type IIA fiber percentage, extracellular matrix, satellite cells per fiber, pennation angle, and physiological CSA are evident in the injured limb compared to the uninjured limb following ACL injury. ${ }^{17}$ Most of these deficits in the injured limb persist despite ACLR and subsequent rehabilitation. ${ }^{17}$ The combination of these factors with muscle size results in significant quadriceps strength deficits after ACL injury and ACLR. A review of 37 studies reported between-limb quadriceps strength deficits ranging from 3-40\% and 3-28\% at six and 12 months post ACLR, respectively. ${ }^{18}$ More recently, Toole et al. ${ }^{19}$ reported $<45 \%$ of a cohort of 115 youth athletes who had undergone ACLR had $<10 \%$ quadriceps strength deficit at the time of return-to-sport. In a large cohort of 450 individuals after ACLR, only $26 \%$ showed $<10 \%$ quadriceps strength deficit six months post-ACLR. ${ }^{20}$

Strength losses following ACLR are not limited solely to the quadriceps. Hamstring, hip, and ankle muscle strength deficits have been reported as well. ${ }^{21}$ Further, deficits in knee extension and knee flexion rate of force development (RFD), ${ }^{22-24}$ reactive strength, ${ }^{25,26}$ and power ${ }^{27-29}$ have also been shown after ACLR. These qualities are fundamental for many athletic endeavors, and ongoing deficits may limit successful return to sport. Not only is the injured limb subjected to these deficits, the contralateral limb also has been shown to experience muscle strength and RFD deficits following ACLR. 30,31

Musculoskeletal deficits after ACL injury and ACLR may also be due to a cascade of events after initial injury in the neurological system, which highlights one example of the interrelated nature of the system components that contribute to goal-directed human movement. Arthrogenic muscle inhibition (AMI) is the inability to fully contract a muscle despite the muscle not having sustained tissue damage. ${ }^{32}$ It has been theorized that inhibition occurs due to decreased spinal reflex excitability that travels to the cen- 
tral nervous system which in turn inhibits muscle contraction. ${ }^{32}$ Prolonged AMI may lead to a delay in optimal loading of the quadriceps due to the inability of the entire motor unit pool to volitionally activate and produce force. Rice et al. ${ }^{32}$ reported that in those with an ACL-deficient knee, $57.1 \%$ failed to fully activate (less than $95 \%$ activation) their quadriceps on their injured side, and $34.2 \%$ failed to do so on their uninjured side. Further, after ACLR, up to $73 \%$ of individuals demonstrate quadriceps activation failure in the injured limb compared to $8 \%$ in the uninjured limb. This indicates that decreased quadriceps activation occurs immediately after injury and persists after surgery. Hart et al. ${ }^{33}$ reported that $21 \%$ of patients after ACLR had quadriceps activation failure of both limbs for up to four years after ACLR. However, Harkey et al. ${ }^{34}$ found no betweenlimb differences in quadriceps activation or spinal reflex excitability at six months and up to 12 years postoperatively, and that spinal reflex excitability did not predict six-month quadriceps activation. Although conflicting evidence exists regarding the mechanisms of AMI after ACL injury, AMI is important to address as soon as possible after both ACL injury and subsequent surgery as it may prolong quadriceps weakness and subsequently influence outcomes such as reinjury rates, patient-reported outcome measures, and early onset OA. ${ }^{35-37}$

Effusion, or increased intraarticular fluid, can stimulate pressure-sensitive mechanoreceptors and may also contribute to AMI. These mechanoreceptors influence groupII joint afferent nerves reported to contribute to inhibition of quadriceps activation. ${ }^{38}$ Further, Rice and colleagues reported that an increased knee effusion reaching an intraarticular pressure of $50 \mathrm{mmHg}$ is associated with increased motor-evoked potentials (MEPs). ${ }^{38}$ Theoretically, increased MEPs should result in increased volitional quadriceps contraction. However, previous studies showed decreased quadriceps volitional contraction after acute knee injury and pain, and Rice et al. speculated that the increased excitability they recorded was an attempted compensatory mechanism to maintain neural drive to the muscular system. ${ }^{38}$ This is supported by Grooms et al. ${ }^{39}$ who found altered activity in corticomotor pathways during a knee extension task between healthy controls and ACLR subjects. This theory may also explain why Lynch and colleagues found no relationship between quadriceps activation and different grades of effusion measured by the stroke test (described later in this commentary). ${ }^{40}$ Thus, it is unclear whether effusion is a direct contributor to AMI, and through what mechanism effusion may cause AMI.

The donor site of the ACL graft may have implications for musculoskeletal health. Several of the more common graft types include the hamstring, patellar, or quadriceps tendon. A systematic review reported mixed evidence for graft-related strength deficits according to graft site, graft preparation, postoperative timeframe, and method of strength assessment. $^{21}$ Regardless, it is important to evaluate quadriceps and hamstring strength at appropriate postoperative timeframes to guide rehabilitation progression. Patellar tendinopathy is a concern in those with bonepatellar tendon-bone autograft, which may also have implications for graft failure if pre-existing patellar tendinopathy is present. ${ }^{41}$ In addition and although uncommon, up to a $0.2 \%$ complication rate of patella fracture or patellar tendon rupture has been reported with the use of a bonetendon-bone graft. ${ }^{42}$ Recognizing the implications of ACL graft donor site should be considered when planning musculoskeletal assessments and interpreting outcomes.

The skeletal system may also demonstrate significant changes in addition to the muscular system after ACL injury. Many changes in bone, cartilage and meniscus have been reported after ACL injury and reconstruction. These include decreased bone mineral density of the hip, ${ }^{43}$ proximal and distal femur, proximal tibia, and calcaneus, ${ }^{44,45}$ altered articular cartilage thickness ${ }^{46-48}$ and composition, ${ }^{49-52}$ and changes in meniscal tissue structure including alteration of the collagen-proteoglycan matrix even in the absence of observed concomitant meniscus tear. ${ }^{53}$ Further, bone bruises occur in $80 \%-90 \%$ of individuals who sustain acute ACL injury, most often in the anterolateral femoral condyle and posterolateral tibial plateau. ${ }^{54,55}$ These bone bruises have been associated with degeneration of chondrocytes and decreased proteoglycans in overlying cartilage. ${ }^{56}$ Bone bruises and associated cartilage degeneration may persist years after injury and may play an important role in the elevated risk for OA development after ACL injury and ACLR. ${ }^{54}$ Although concomitant meniscus and chondral damage at the time of ACL injury increases the odds for knee OA development, ${ }^{57}$ it does not explain all of the risk. Alterations in factors such as muscle strength, biomechanical movement patterns, and participation in cutting and pivoting activities may inadequately load or overload the connective tissue structures of the knee joint including bone and articular cartilage and increase risk for OA development.

\section{CLINICAL ASSESSMENT OF MUSCULOSKELETAL HEALTH AFTER ACL RECONSTRUCTION}

The authors encourage rehabilitation professionals to understand sport-specific physical demands and utilize any available strength and performance normative data to guide the clinical reasoning process (Appendices A and B). The physical demands inherent to sport performance require the integration of multiple physiologic systems into movement solutions that satisfy task demands. ${ }^{1}$ Identification of impairments across multiple systems is recommended, but this section will focus on several clinically available methods that can be used after ACL injury and reconstruction to measure modifiable aspects of the musculoskeletal system. Limb symmetry indices (LSI) are often used to interpret muscle strength and functional test results although recent evidence suggests LSI may overestimate injured limb strength and function due to decreased performance of the uninjured limb. ${ }^{30,31,58}$

\section{JOINT EFFUSION}

Circumferential measurement of the knee with a tape measure is a simple clinical assessment of knee effusion and swelling. It should be noted that clinical measurement of knee effusion is indirect in nature, as knee effusion is an intraarticular phenomenon and may be influenced by ex- 
traarticular swelling. Measurement should be taken with the tape measure positioned one centimeter superior to the patella, ${ }^{59}$ and care should be taken to avoid an ellipsoid path with the tape measure while maintaining consistent tension. Measuring tapes with a spring-loaded Gulick attachment offer the benefit of standardized tension application during measurement. Alternatively, the stroke test is a reliable and more direct assessment of knee effusion after ACL injury. ${ }^{60}$ This may be important to assess as even small amounts of effusion may be associated with AMI. 38 This test uses a five-point ordinal scale $(0$, trace, $1+, 2+, 3+)$ to measure effusion that produces no fluid wave upon at the medial side of the knee upon the downstroke (effusion $=0$ ) to effusion that cannot be moved out of the medial aspect of the knee during the upstroke (effusion $=3+$ ). Knee effusion should be serially assessed to appropriately progress exercise and activity levels during rehabilitation. ${ }^{61}$

\section{RANGE OF MOTION}

The most common clinical assessment of knee range of motion (ROM) is goniometry. ROM goals after ACL injury and ACLR include achieving full terminal knee (hyper)extension and flexion comparable to the contralateral limb. A loss of only three to five degrees of knee extension has been associated with OA development and a worse long-term outcome. ${ }^{62}$ Terminal extension should also be exhibited actively as a patient should be able to lift their heel in supine while keeping their knee in contact with the table. Inability to achieve this may be due to ongoing AMI, quadriceps weakness, or ROM deficits. A loss of maximal knee joint flexion may influence gait during high speed running as maximal knee flexion is reached during the swing phase $\mathrm{e}^{13}$ as well as sport-specific tasks that require deep squatting (e.g. baseball catcher).

\section{MUSCLE GIRTH}

Quadriceps size can be indirectly assessed via muscle girth with circumferential measurements using a tape measure. Positioning the tape $20 \mathrm{~cm}$ above the anteromedial joint line is supported as the most relevant level to detect between-limb differences. ${ }^{63}$ It should be noted that the participants from Laupattarakasem et $\mathrm{al}^{63}$ had a mean height of $169 \mathrm{~cm}$, and the position of the tape relative to the joint line may vary based on the height and limb length of the individual. Although circumferential girth may underestimate losses in actual muscle CSA, it has been correlated with muscle CSA and therefore remains a clinically relevant metric. 64

\section{MUSCLE STRENGTH}

Muscle strength can be defined as a muscle's ability to exert force on an external object. ${ }^{65}$ This must be measured with isolated single joint testing of the targeted muscle group in order to eliminate compensations from other muscle groups (e.g. hip extensors during a leg press). When assessing single joint movements, torque may be calculated which takes into account limb segment length. Normalizing torque to body mass allows for comparisons across populations. The authors recommend a target for normalized isometric knee extension torque at 60 degrees of knee flexion to be $3 \mathrm{Nm}$ / kg. ${ }^{66,67}$ Isokinetic dynamometers are the current gold standard for single joint testing of muscular torque, although more clinically available dynamometers such as in-line or hand-held (HHD) options have been shown to give valid and reliable measurements when set up in a rigid and repeatable manner. ${ }^{68}$ This may be implemented using belt fixation 68 as previously reported. Options for dynamometers are currently available at a price point that is much more cost-effective than seen previously, which could increase utilization of clinically meaningful measurements.

A one-repetition maximum (1RM) test aims to measure the muscle force exerted in one maximal effort with good form, and is also quantified as the maximum load that can be lifted one time. ${ }^{69}$ Specific to the quadriceps muscle, using a leg extension machine to test 1RM from 90-45 degrees is also supported as a strength assessment, although this method may be more useful for ruling in asymmetry than ruling it out. ${ }^{70} \mathrm{~A}$ reliable and repeatable testing set-up for between-limb comparisons or serial testing of the injured limb is necessary for valid muscle strength assessments.

Other muscles to consider for examination include the hip abductors, hip extensors, and ankle plantarflexors. Alternative assessment of these muscle groups may include performing a task for repetitions to failure or repetitions completed in a given time frame such as 30 seconds. Ankle plantarflexor assessment can be completed with single-leg heel raises. Hip extensors and hamstring assessment can be completed with single-leg elevated bridges in varying degrees of hip and knee flexion. Although utilizing repetitions to failure or repetitions in a time frame for the above assessments can be done clinically, the clinician should acknowledge that proxy measures may not accurately assess maximum strength and could be more a reflection of muscle endurance or some other confounder.

In addition to single joint assessment, multi-joint testing can be completed to assess the lower extremity kinetic chain. Multi-joint testing can include qualitative evaluation assessment tools when used in a valid and reliable manner, such as the qualitative assessment scheme proposed by Herrington and colleagues which utilizes dichotomous criteria to rate the movement strategy of the arms, trunk, pelvis, thigh, knee, and foot during the specified tasks. ${ }^{71,72}$ Quantitative measures should also be obtained, and various multi-joint assessments have been utilized such as lateral or anterior step-downs, a single-leg squat test, and singleleg leg press test. ${ }^{73-75}$ Herrington et al recommend that the task requires a minimum of 90 degrees of knee flexion to increase the overall muscular demand compared to more shallow angles of knee joint flexion. The leg press may be used to assess for a 1RM or for reps to failure at a given intensity such as $100 \%$ bodyweight. For step-downs or singleleg squats, repetitions to failure or repetitions completed in a given timeframe such as 30 seconds may be utilized as discussed above, again acknowledging that this is not a maximum strength assessment.

\section{RATE OF FORCE DEVELOPMENT (RFD)}

Explosive strength is the ability to produce force rapidly and 
is typically assessed via RFD during isometric tasks by evaluating rate of change in force over some time epoch which is represented by the slope of the force-time curve (e.g. slope of force-time curve between $0-250$ milliseconds). ${ }^{76}$ Rate of torque (RTD) or RFD is commonly measured using an isokinetic dynamometer for single joint tasks or force plates for multi-joint tasks such as an isometric mid-thigh pull. Access to these devices is necessary but insufficient for accurate RTD/RFD measurement since assessment is challenging and current methods of both testing and interpretation of results vary widely in the literature. For example, it is suggested that isokinetic dynamometers are modified during RTD/RFD assessment to account for factors such as system compliance, sampling rate, and software processing to obtain a reliable measure. ${ }^{77}$ Additionally, previous literature reports RTD/RFD over various epochs (e.g. 0-100 milliseconds, $50-150$ milliseconds, $20 \%-80 \%$ of peak, etc.), as an average, or as a peak. ${ }^{77,78}$ Thus, one must be cognizant of these factors when interpreting results. ${ }^{77}$ Regarding assessment without access to modified isokinetic dynamometers or expensive force plates, valid and reliable methods have yet to become widely available to clinicians. However, affordable force plates and software are becoming increasingly available and may present a future direction for clinically assessing explosive strength via RTD/RFD. Recently, HHD measurements of quadriceps peak torque and late RFD (250 $\mathrm{ms}$ ) derived from raw data demonstrated acceptable validity when compared to isokinetic dynamometry; however, this feature is not yet clinically available in most HHD testing devices. ${ }^{79}$

\section{REACTIVE STRENGTH}

Reactive strength can be measured to determine a patient's ability to utilize the stretch-shortening cycle and quickly change from eccentric to concentric muscle action as performed during plyometric activities. Examples of clinical assessments include modified reactive strength index (RSImod) during a single or double leg vertical countermovement jump ${ }^{80}$ and reactive strength index (RSI) during a drop vertical jump (DVJ). ${ }^{81}$ RSI can be calculated by dividing flight time by ground contact time, although other calculations also exist. Jump height and RSI can be assessed with force plates, but also can be reliably measured clinically with the My Jump 2 application (available for download using Apple App Store for iOS, Google Play for Android). ${ }^{82}$ If assessing a DVJ, it should be noted that RSI will differ based on the height from which the drop is performed. Thus, a consistent height should be used between limbs and for reassessments. Repeated hopping such as the side hop test ${ }^{83}$ may also be used as a surrogate clinical measure of reactive strength. Reactive strength tests should also be evaluated qualitatively as discussed above with multi-joint strength.

\section{HOP TESTS}

Single leg hop tests have long been used as a functional assessment after ACLR, ${ }^{84}$ as they have demonstrated acceptable reliability to measure progress during rehabilitation. ${ }^{85}$ However, it should be noted that hop tests are a valid measure of a patient's ability to perform a hopping task rather than assessing any specific physical quality. Because of this, a critical examination of single leg hop tests showed that clinicians tend to overestimate lower extremity function when using hop distance alone. ${ }^{86}$ Given these inherent limitations, it may be necessary to rethink the interpretation of hop testing or add qualifications to the test such as evaluating two-dimensional movement quality during single leg hop tests which can be done using commercially available video cameras and video analyzing software (Kinovea 0.8.15 available at Kinovea.org), ${ }^{87}$ as patients postACLR often demonstrate deficiencies during landing compared to the uninjured limb and uninjured individuals. ${ }^{88}$

Finally, LSIs for muscle and lower limb performance (e.g. muscle strength, rate of force development, reactive strength, single-legged hop tests) that reach $90 \%$ are often considered functional targets during rehabilitation. ${ }^{89}$ However, LSI has been reported to overestimate injured limb function due to deterioration of the uninjured limb. ${ }^{30,31,58}$ Other criteria such as pre-injury baseline measures or normative values can provide valuable alternatives to LSIs. However, in the absence of these data, LSI provides a useful metric during rehabilitation when taken in context of known shortcomings.

\section{MULTI-PHYSIOLOGIC SYSTEM INTERVENTIONS FOR THE MUSCULOSKELETAL SYSTEM AFTER ACLR}

Addressing changes in the musculoskeletal system after ACL injury and ACLR should be a priority given their associations with altered biomechanical movement patterns, poor long-term function, re-injury risk, and risk of OA development. ${ }^{36,90-92}$ By appropriately addressing musculoskeletal impairments, it allows for further integration of interventions to allow for recovery of other components (cardiopulmonary, nervous, integumentary) with the aim to ultimately resolve movement dysfunction. Foundational concepts and progression principles in strength and conditioning should be implemented through a multi-physiologic system lens, recognizing that strength training impacts multiple body systems important for human movement. Primary principles to be discussed include progressive overload, specificity, and variation. ${ }^{93}$ These principles can be used to target any fitness parameter (endurance, strength, power, speed, etc.).

\section{INTERVENTIONS FOR RANGE OF MOTION}

Addressing extension loss in the early post-operative period should be a high priority. Ideally restoring full knee extension should also be accomplished pre-operatively as risk of prolonged extension loss after surgery has been reported to be five times more likely if full extension was not achieved prior to surgery. ${ }^{94}$ Risk of developing arthrofibrosis is two and eight times more likely if extension loss remains at three and six weeks post-operatively, respectively. ${ }^{95}$ After surgery, the tensile strength of the skin gradually improves over time, so one must also be mindful of integumentary system health and the healing surgical site when applying ROM interventions. ${ }^{96}$ 
When addressing ROM deficits, the clinician must first consider factors that may be limiting the ROM. This may be pain, effusion, muscle guarding, or arthrofibrosis. If pain and guarding are limiting factors, techniques and modalities such as electrical stimulation, cryotherapy, joint mobilizations, or soft tissue massage may be helpful. ${ }^{97,98}$ For effusion one may consider pneumatic compression devices, active range of motion, and adherence to loading principles. ${ }^{99}$ Patients should also be instructed in self stretches for knee extension at least three times per day which may include supine heel props, self-applied overpressure, and active quad contractions in terminal extension. ${ }^{10}$ Patellar mobility may limit ROM and can effect patellofemoral arthrokinematics. ${ }^{100}$ Therefore the clinician and patient may implement patella mobilizations to ensure appropriate mobility. If loss of knee extension persists, implementing the concept of total end range time (TERT) is recommended. This may include low load long duration stretching in supine with the heel propped and 5-15 pounds placed on the distal thigh for 10-15 minutes at a time for $60+$ minutes per day. ${ }^{101}$ The intensity of the stretch should allow for the patient to tolerate the stretch without pain or muscle spasm. Although less frequently implemented, persistent extension loss may also be treated with splinting or additional surgical procedures. ${ }^{10,102}$ Knee flexion ROM should also be progressed during the early post-operative period. General guidelines include targets of 90-100 degrees by one week post-operatively and increases of $\sim 10$ degrees per week after that. This may be delayed if there are concomitant injuries or procedures (e.g. meniscus repair), or excessive effusion. Knee flexion ROM can be achieved with exercises such as heel slides, wall slides, or stationary biking. ${ }^{10}$ To achieve full terminal flexion that is requisite of high speed running and other sport-specific tasks later in rehabilitation, patients may utilize a short kneeling position to attempt to sit on their heels and active heel to gluteal drills in standing. Achieving normal ROM is an integral initial step for recovery of the musculoskeletal system and its components, but also contributes to carrying out movement-related interventions that impact other physiologic systems after ACLR.

\section{MUSCULOSKELETAL INTERVENTION PRINCIPLES}

\section{PROGRESSIVE OVERLOAD}

Progressive overload is the gradual increase in demand placed upon a system in response to the adaptation to previously imposed demands. Exercise prescription should aim to apply an appropriate stress or dosage to elicit a desired adaptation within a system at that time point. This dosage is affected by the manipulation of variables including: intensity, volume load (reps x sets x resistance), frequency, repetition speed and tempo, exercise selection and order, and rest periods. These variables are manipulated so that the dose is sufficient to elicit adaptation but within an individual's recovery capacity. The individual response can be affected by several factors including comorbidities, training history, time, nutrition, stress, and sleep. Tolerance to exercise loads can be monitored via pain and effusion (see earlier sections regarding assessment). Musculoskeletal adap- tations to resistance training are typically better understood, but adaptations in other physiologic systems should be considered when developing treatment plans to address movement limitations. Some of the nervous system adaptations to resistance training include changes to higher brain centers, motor unit recruitment, and the neuromuscular junction. ${ }^{69}$ Acute responses to resistance training have been described for the cardiopulmonary system and include increased cardiac output, greater blood flow to working muscles, among several others. In essence, resistance training adaptations are not isolated to the musculoskeletal system but rather impact multiple physiologic systems that are important for goal-directed human movement.

\section{SPECIFICITY}

The SAID principle, which is an acronym for "specific adaptation to imposed demands", states that any given adaptation will be specific to the applied stimulus. ${ }^{69}$ While there can be complimentary adaptations to the stimulus across multiple fitness and musculoskeletal adaptations, specific training goals are most effectively addressed by applying a training stimulus that specifically targets the desired adaptation. This idea compliments the principle of progressive overload discussed previously as both work together to ensure progress towards the desired goal.

\section{VARIATION}

Variation is the process of changing program variables so training stimuli are challenging for a system. This is necessary because as individuals adapt to training, desensitization to the training stimulus can occur and the magnitude of adaptations can decrease. Variation is commonly achieved through periodization, for which several models have been developed and demonstrated effectiveness. ${ }^{103}$ It should be noted that nearly all available literature on periodization is conducted in healthy individuals rather than an injured or post-surgical population. Nevertheless, the principles can be applied effectively to individuals after ACL injury and ACLR when combined with clinical reasoning and monitoring.

Linear or classic periodization involves structuring a program with progressive decrease of volume and increase in load across several mesocycles. A mesocycle has been described as a medium-sized training cycle with two to six weeks being the most typical duration. ${ }^{69}$ Each cycle prioritizes one fitness parameter and progresses to the next parameter in a predictable, structured manner. In rehabilitation, this typically begins with relatively low intensities and high volumes, and gradually progresses to higher intensities and lower volumes.

Nonlinear or undulating periodization utilizes either systematic or random alteration of intensity and volume within a training cycle. This can occur daily or weekly. This allows for multiple fitness parameters to be developed simultaneously. No differences between linear and nonlinear periodization have been established in the healthy population. 104

Block periodization involves attempting to maximize 
Table 1. Training Variables for Fitness Parameters

\begin{tabular}{|c|c|c|c|c|c|c|}
\hline $\begin{array}{l}\text { Training } \\
\text { Goal }\end{array}$ & Volume & Intensity & Frequency & $\begin{array}{l}\text { Exercise } \\
\text { selection }\end{array}$ & $\begin{array}{l}\text { Rest } \\
\text { Periods }\end{array}$ & Other \\
\hline \multirow[t]{2}{*}{$\begin{array}{l}\text { Local muscle } \\
\text { endurance }\end{array}$} & $\begin{array}{l}\text { Option 1: } 10-25 \text { reps } \\
\text { of multiple sets per } \\
\text { exercise }\end{array}$ & $\begin{array}{l}\text { Option 1: } \\
\text { Light } \\
\text { (<10-15RM) }\end{array}$ & \multirow[t]{2}{*}{$\begin{array}{l}\text { Novice: } \\
\text { 2-3x/wk } \\
\text { Advanced: } \\
\text { 4-6x/wk } \\
\text { for muscle } \\
\text { group } \\
\text { split } \\
\text { routines }\end{array}$} & $\begin{array}{l}\text { Option 1: } \\
\text { Unilateral } \\
\text { and } \\
\text { bilateral; } \\
\text { single } \\
\text { and } \\
\text { multi- } \\
\text { joint }\end{array}$ & \multirow[t]{2}{*}{$\begin{array}{l}1-2 \text { min } \\
\text { for high } \\
\text { reps } \\
(15+) \\
<1 \text { min } \\
\text { for low } \\
\text { reps } \\
(<15)\end{array}$} & \multirow[t]{2}{*}{$\begin{array}{l}\text { Slow velocities } \\
\text { for < } 15 \text { rep } \\
\text { schemes; } \\
\text { Moderate to } \\
\text { fast velocities } \\
\text { for } 15+\text { rep } \\
\text { schemes }\end{array}$} \\
\hline & $\begin{array}{l}\text { Option } 2 \text { (EMOM): } \\
5-10 \text { sets of } 3-10 \text { reps }\end{array}$ & $\begin{array}{l}\text { Option } 2 \\
\text { (EMOM): } \\
60-80 \% \\
1 \mathrm{RM}\end{array}$ & & $\begin{array}{l}\text { Option } 2 \\
\text { (EMOM): } \\
\text { Mostly } \\
\text { multi- } \\
\text { joint }\end{array}$ & & \\
\hline Hypertrophy & $\begin{array}{l}\text { Novice: } 1-3 \text { sets of } \\
\text { 8-12 reps per exercise } \\
\text { Advanced: } 3-6 \text { sets of } \\
\text { 1-12 reps per } \\
\text { exercise; } 10+\text { total } \\
\text { sets per muscle group } \\
\text { per week }\end{array}$ & $\begin{array}{l}\text { Novice: } \\
\text { 70-85\% } \\
\text { 1RM } \\
\text { Advanced: } \\
\text { 70-100\% } \\
\text { 1RM }\end{array}$ & $\begin{array}{l}2-3 x / \text { wk } \\
\text { per } \\
\text { muscle } \\
\text { group }\end{array}$ & $\begin{array}{l}\text { Single } \\
\text { and } \\
\text { multi- } \\
\text { joint; } \\
\text { OKC and } \\
\text { CKC }\end{array}$ & $\begin{array}{l}1-2 \text { min } \\
\text { that can } \\
\text { be } \\
\text { extended } \\
\text { to } 2-3 \\
\text { min with } \\
\text { heavy } \\
\text { loading }\end{array}$ & $\begin{array}{l}\text { Muscle actions } \\
\text { should include } \\
\text { con, ecc, iso at } \\
\text { long muscle } \\
\text { lengths; } \\
\text { Controlled } \\
\text { velocities }\end{array}$ \\
\hline Strength & $\begin{array}{l}\text { 1-3 work sets per } \\
\text { exercise; } 3-10 \text { reps } \\
\text { (progressing to lower } \\
\text { rep range as training } \\
\text { age/status and } \\
\text { intensity increases) }\end{array}$ & $\begin{array}{l}\text { Novice: } \\
\text { 70-85\% } \\
\text { 1RM } \\
\text { Advanced: } \\
\text { 80-100\% } \\
\text { 1RM }\end{array}$ & $2-3 x / w k$ & $\begin{array}{l}\text { Unilateral } \\
\text { and } \\
\text { bilateral; } \\
\text { single } \\
\text { and } \\
\text { multi- } \\
\text { joint; } \\
\text { OKC and } \\
\text { CKC }\end{array}$ & $\begin{array}{l}2-3 \\
\text { minutes } \\
\text { for multi } \\
\text { joint/ } \\
\text { large } \\
\text { muscle } \\
\text { groups } \\
\text { 1-2min } \\
\text { for single } \\
\text { joint/ } \\
\text { small } \\
\text { muscle } \\
\text { groups }\end{array}$ & $\begin{array}{l}\text { Muscle actions } \\
\text { should include } \\
\text { con, ecc, iso; } \\
\text { intent for max } \\
\text { velocity during } \\
\text { concentric }\end{array}$ \\
\hline Power & $1-3$ sets of $3-6$ reps & $0-60 \% 1 R M$ & $\begin{array}{l}\text { Novice: } \\
\text { 2-3x/wk } \\
\text { Advanced: } \\
\text { 4-5x/wk }\end{array}$ & $\begin{array}{l}\text { Mostly } \\
\text { multi- } \\
\text { joint }\end{array}$ & $\begin{array}{l}2-3 \\
\text { minutes } \\
\text { for } \\
\text { complete } \\
\text { recovery }\end{array}$ & $\begin{array}{l}\text { Maximal } \\
\text { intent with } \\
\text { each rep and } \\
\text { minimal drop } \\
\text { off in velocity }\end{array}$ \\
\hline
\end{tabular}

$\mathrm{EMOM}=$ every minute on the minute, $\mathrm{RM}=$ repetition maximum, $\mathrm{OKC}=$ open kinetic chain, $\mathrm{CKC}=$ closed kinetic chain, wk= week, $c 0 n=$ concentric, ecc $=$ eccentric; iso= isometric

adaption for one specific parameter in a given time period, typically within two to four weeks. This allows for the maintenance of the most important physical qualities for an athlete's sport. Each block includes three phases: accumulation which includes a high volume of general exercise at 50-70\% $1 \mathrm{RM}$ to build work capacity; transmutation, which includes more specific exercises at $75-95 \% 1 \mathrm{RM}$; and realization, which includes even more specific movements when compared to the transmutation phase with the goal of $>90 \%$ 1RM. ${ }^{105}$

Linear periodization may be most appropriate for initially structuring a program for an individual after ACL injury or ACLR. This presents a logical starting place and a safe, effective progression when aiming to address the musculoskeletal deficits previously described. This programming can be accomplished utilizing Vermeil's Hierarchy, a widely utilized model of athletic development that is designed to adequately load the musculoskeletal system in a systematic and logical manner. ${ }^{106}$ Implementation of this model first requires the development of a patient's work capacity, which is the ability to sustain work and accumulate workload to prepare the body to tolerate increases in load. This progresses in a stepwise manner to strength, explosive strength, reactive strength, and speed. While qualities within the hierarchy can be trained concurrently, optimal development of any one quality in the hierarchy requires the preceding quality to be adequately developed. By definition, training multiple qualities concurrently means that the program shifts more to non-linear periodization, although one quality may be emphasized. Table 1 depicts training variables based on the goal. ${ }^{93}$ The reader is referred to Table 2 for an example of programming schemes utilizing an adaptation of the hierarchy. 
Table 2. Example of Programming Progression Utilizing Vermeil's Hierarchy

\begin{tabular}{|c|c|c|c|c|c|c|}
\hline Parameter & Duration & Volume & Intensity & Frequency & Exercise Examples & $\begin{array}{l}\text { Other } \\
\text { Considerations }\end{array}$ \\
\hline $\begin{array}{l}\text { Work } \\
\text { Capacity/ } \\
\text { Endurance }\end{array}$ & $\begin{array}{l}2-4 \\
\text { weeks }\end{array}$ & $\begin{array}{l}1-2 \\
\text { exercises } \\
\text { per } \\
\text { muscle } \\
\text { group; } \\
2-4 \text { sets } \\
\text { x } 12-20 \\
\text { reps }\end{array}$ & $\begin{array}{l}\text { Low - } \\
\text { moderate } \\
(<70 \% \\
\text { 1RM) }\end{array}$ & $3 x / w k$ & $\begin{array}{l}\text { leg press, leg ext, leg } \\
\text { curl, bridges, sidelying } \\
\text { hip abduction, heel } \\
\text { raises }\end{array}$ & $\begin{array}{l}\text { BFR, NMES, } \\
\text { cross- } \\
\text { education }\end{array}$ \\
\hline $\begin{array}{l}\text { Hypertrophy/ } \\
\text { strength }\end{array}$ & $\begin{array}{l}4-8 \\
\text { weeks }\end{array}$ & $\begin{array}{l}\text { 6-10 } \\
\text { sets } x \\
8-12 \\
\text { reps per } \\
\text { muscle } \\
\text { group }\end{array}$ & $\begin{array}{l}\text { Moderate } \\
(\sim 70-80 \% \\
1 \text { RM) }\end{array}$ & $2-3 x / w k$ & $\begin{array}{l}\text { Leg press, leg ext, leg } \\
\text { curl, squat and lunge } \\
\text { variations, deadlift } \\
\text { variations, banded } \\
\text { lateral walks, heel raises }\end{array}$ & $\begin{array}{l}\text { NMES, cross- } \\
\text { education, } \\
\text { supramaximal } \\
\text { eccentrics }\end{array}$ \\
\hline Strength & $\begin{array}{l}4-8 \\
\text { weeks }\end{array}$ & $\begin{array}{l}3-5 \text { sets } \\
\times 5-8 \\
\text { reps }\end{array}$ & $\begin{array}{l}\text { Moderate- } \\
\text { high } \\
\text { (>80\% } \\
\text { 1RM) }\end{array}$ & $2-3 x / w k$ & $\begin{array}{l}\text { Leg press, leg ext, leg } \\
\text { curl, squat and lunge } \\
\text { variations, deadlift } \\
\text { variations, heel raises }\end{array}$ & $\begin{array}{l}\text { NMES, Cross- } \\
\text { education, } \\
\text { supramaximal } \\
\text { eccentrics }\end{array}$ \\
\hline $\begin{array}{l}\text { Explosive } \\
\text { Strength/ } \\
\text { RFD }\end{array}$ & $\begin{array}{l}2-4 \\
\text { weeks }\end{array}$ & $\begin{array}{l}3-6 \text { sets } \\
\times 3-6 \\
\text { reps }\end{array}$ & $\begin{array}{l}\text { Low (BW } \\
\text { or 30-45\% } \\
\text { 1RM) }\end{array}$ & $2-3 x / w k$ & $\begin{array}{l}\text { Squat jumps, drop lands, } \\
\text { ballistic isometrics } \\
\text { (IMTP or leg press), } \\
\text { accels, decels, Olympic } \\
\text { derivatives (i.e. jump } \\
\text { shrug) }\end{array}$ & $\begin{array}{l}\text { Perform } \\
\text { exercises with } \\
\text { intent of max } \\
\text { velocity }\end{array}$ \\
\hline $\begin{array}{l}\text { Elastic/ } \\
\text { Reactive } \\
\text { Strength }\end{array}$ & $\begin{array}{l}2-4 \\
\text { weeks }\end{array}$ & $\begin{array}{l}3-6 \text { sets } \\
\times 3-6 \\
\text { reps }\end{array}$ & $\begin{array}{l}\text { Low (BW } \\
\text { or }<30 \% \\
1 \mathrm{RM})\end{array}$ & $1-3 x / w k$ & $\begin{array}{l}\text { Ankling, CMJ, DVJ, } \\
\text { sprints (>7m/s) }\end{array}$ & $\begin{array}{l}\text { Minimize } \\
\text { ground contact } \\
\text { time }\end{array}$ \\
\hline
\end{tabular}

Accels= accelerations, decels= decelerations, $\mathrm{RM}=$ repetition maximum, $\mathrm{RFD}=$ rate of force development, $\mathrm{BW}=$ body weight, ext= extension, $\mathrm{BFR}=\mathrm{blood}$ flow restriction, $\mathrm{NMES}=$ neuromuscular electrical stimulation, IMTP= isometric mid-thigh pull, CMJ= countermovement jump, DVJ= drop vertical jump, $\mathrm{m} /=$, meters $/$ second, $w \mathrm{k}=\mathrm{week}$

\section{INTERVENTIONS FOR ARTHROGENIC MUSCLE INHIBITION}

A multi-physiologic systems approach to target AMI requires integrative knowledge of the nervous system to appropriately incorporate interventions within a comprehensive treatment plan. The most common intervention for AMI after ACL injury is neuromuscular electrical stimulation (NMES). Fitzgerald et $\mathrm{al}^{107}$ showed that a modified NMES program (twice per week, $2500 \mathrm{~Hz}$ alternating current, two second ramp up and down, ten second stimulation period with visible contraction, and 50 second rest period for 11-12 minutes) as an adjunct to standard rehabilitation was more effective in restoring quadriceps activation at 12 and 16 weeks postoperatively compared to standard rehabilitation alone. More recent studies also support these findings. ${ }^{108,109}$ Lepley et al. ${ }^{109}$ compared an NMES-only group to NMES with eccentric strength training, eccentric strength training only, and standard care. Their findings demonstrated that both eccentric strength training alone and NMES with eccentric strength training showed less quadriceps strength and activation loss at time of returnto-sport testing compared to preoperative testing. Although NMES is commonly used in early stages of ACLR rehab, these findings suggest that NMES may be implemented throughout the rehabilitation stages to influence quadriceps strength.

In addition to active interventions, passive modalities may also help with increased quadriceps activation such as specific applications of transcutaneous electrical nerve stimulation (TENS) ${ }^{110}$ or focal joint cooling. ${ }^{111}$ Although the two aforementioned investigations on TENS and focal joint cooling prior to rehabilitation seem to be effective interventions for AMI, the generalizability of applying these interventions to ACLR populations is limited due to the populations studied and clinical feasibility of the treatment protocols. It is important to be mindful that sensory deficits around the knee can persist for months or years after ACLR as a result of the surgical procedure, ${ }^{112}$ which may place patients at elevated risk for other sensory impairments including burns and poor thermoregulation. ${ }^{113}$

\section{INTERVENTIONS FOR MUSCLE STRENGTH}

Adequate muscle strength provides the foundation for RFD and reactive strength required by most sporting movements and activities. It has been suggested that until a healthy individual can squat 1.6 times their body mass, continued benefits from strength training will occur. ${ }^{114}$ Haff and Nimphius ${ }^{115}$ suggest that for healthy individuals the associations among strength, power, and RFD are maximized when a $2 x$ body mass squat can be achieved. Although RFD and power training modalities may be implemented prior to reaching the $2 x$ body mass squat threshold for most individuals, achieving this squat threshold is indicative of strength no longer being the main limitation for the ability to pro- 
duce force. Muscle hypertrophy is stimulated via muscle mechanical tension which leads to stimulation of pathways contributing to anabolism and muscle growth. ${ }^{116}$ These pathways can also be stimulated via metabolic stress and accumulation of metabolites causing hypoxia within a muscle. Although debated, muscular strength can be influenced by muscle CSA, so any increases in hypertrophy may also contribute to potential for strength. ${ }^{117}$ Strength is influenced by many other factors as well including muscle architecture, biomechanics, and several neural factors including motor unit recruitment and synchronization, firing frequency, and inter-muscular coordination. ${ }^{117}$ Further, it is important to be aware that atrophy after traumatic joint injury may occur through different mechanisms than disuse atrophy. ${ }^{118}$ Emerging evidence suggests neurophysiological changes occur after ACL injury which affect the corticospinal and spinal reflexive pathways to the quadriceps muscle. ${ }^{119,120}$ If these pathways are not restored by suggested interventions for AMI, then hypertrophy may not occur despite attempts of mechanical loading. Therefore, the importance of addressing AMI in conjunction to traditional methods of muscle strengthening must be stressed. Training for hypertrophy and strength should utilize the variables in Table 1 to provide these stimuli. In addition, the rehabilitation professional may consider the following concepts:

\section{VOLUME AND INTENSITY}

Higher volumes tend to be more effective than lower volumes for muscle growth to a certain extent, possibly due to inducing more metabolic stress and acute local hypoxia within a muscle. ${ }^{121}$ Schoenfeld et al. ${ }^{122}$ reported that performing 10 or more sets per muscle group per week trended toward greater hypertrophy than performing less than 10 sets. However, too much volume can begin to exceed the ability of the muscle to recover and diminish the hypertrophic response. The optimal volume of strength training varies among individuals, so monitoring and feedback should be utilized to ensure appropriate recovery. When examining the interactions between musculoskeletal interventions and the cardiopulmonary system, heavy resistance training does little to enhance long-term resting cardiac function, but some cardiovascular benefits may be observed with a high volume program that includes shorter rest periods such as circuit training. ${ }^{69}$

Patients' tolerance to exercise can be monitored through assessment of knee soreness via visual analog scale or using soreness rules (knee soreness experienced during warmup, within session, or the following day) to appropriately progress or regress exercise. ${ }^{123}$ Additionally, daily joint effusion can be assessed via limb circumference at the patella or with the stroke test as previously described. ${ }^{60,124}$ An acute change after exercise of one cm of effusion or a onestep increase on the stroke test has been suggested to indicate excessive tissue overload. ${ }^{75}$ The American College of Sports Medicine guidelines recommend exercising at $>70 \%$ 1 RM for muscle hypertrophy and $>60-80 \% 1$ RM for strength depending on training status. For an individual's knee to tolerate these intensities after ACLR, a periodized program should be implemented.
Training to failure is commonly utilized in healthy individuals and is defined here as performing consecutive repetitions of an exercise until the concentric portion can no longer be completed for another repetition or completion would require a significant change in form. While training to failure is generally not necessary to elicit adaptations in hypertrophy and strength, it does ensure that the dosage is sufficient for these adaptations. Motor unit activation is increased as a muscle becomes fatigued and new motor units are recruited to complete the repetitions. Utilizing greater loads will also elicit increased motor unit activation, but lower loads may be required in the earlier phases of rehabilitation when higher loads are not tolerated or safe. Blood flow restriction (BFR) is an intervention to augment taking low loads to failure and has been shown to be an effective hypertrophic stimulus. ${ }^{125}$ The reader is referred to recent publications ${ }^{126,127}$ for considerations and application of BFR. To maximize effects from training to failure, adequate rest cycles are required to avoid overtraining and mitigating positive hypertrophic adaptations.

\section{CONTRACTION TYPE CONSIDERATIONS}

Concentric, eccentric, and isometric muscle contractions should all be included in a comprehensive rehabilitation program following ACLR. Isometric exercises allow for greater force production than concentric contractions and can be implemented with multi-joint exercises such as leg press or an isometric mid-thigh pull, or with single joint exercises such as leg extensions or leg curls. Strength improvements with isometric exercise tend to be largest at the joint angles in which the exercise is completed, so angle-specific weaknesses can be targeted with this contraction type. Further, lengthened state isometrics may be more effective for hypertrophy and carryover of strength gains throughout the range. ${ }^{128}$

Previous evidence has shown that supramaximal eccentric exercises may lead to enhanced adaptations of hypertrophy, strength, RFD, and reactive strength compared to isometric contractions and traditional isotonic exercises involving a concentric and submaximal eccentric phase. ${ }^{129-131}$ To elicit the increased muscle forces that eccentric exercise affords, the load usually must be supramaximal relative to the concentric force producing capacity. This can be implemented in rehabilitation by performing the concentric portion of an exercise bilaterally and subsequently performing the eccentric portion unilaterally. It is important that the load selected for this is supramaximal for one limb to complete concentrically. An example that is widely available includes a patient attempting a single limb leg extension and increasing the weight until they are no longer able to complete the concentric portion. Then they are instructed to complete the exercise by pushing the weight up with both legs, removing the uninjured leg from the plate, and using the injured leg to lower the weight through the full range to the starting position (Figure 1). Other examples include training on a flywheel device or isokinetic dynamometer. 
BIOMECHANICAL PRINCIPLES DURING STRENGTH TRAINING

Exercise selection and coaching should be based on biomechanical principles to ensure that specific muscle deficits are addressed. Using both open kinetic chain (OKC) and closed kinetic chain (CKC) exercises in clinical rehabilitation will maximize the likelihood that this is accomplished. The primary advantage of OKC exercises is the constraint it imposes on the training task which ensures that the target tissue is addressed. This compliments the higher systemic and coordinative demands seen in CKC exercises. Therefore, both should be utilized in a comprehensive program. Because compensatory patterns to decrease quadriceps muscle utilization are common during CKC strengthening exercises, clinicians should also implement single-joint OKC exercises to facilitate quadriceps strengthening. OKC in addition to CKC exercises has been shown to be more effective at increasing quadriceps strength compared to CKC alone following ACLR. ${ }^{132}$ Additionally, OKC and CKC movements have been reported to have different patellofemoral joint reaction forces at different ranges of motion. OKC results in greater patellofemoral force in lower knee flexion angles while CKC movements will have greater force in higher flexion angles. ${ }^{133}$ Therefore, these may be used concurrently in a program in order to load the knee and quadriceps muscle throughout the range of motion while respecting the patellofemoral joint as it adapts to increased loading. OKC knee extension has been the topic of considerable debate due to potential safety concerns and graft implications, although these concerns may not be warranted and have been challenged. 134 OKC knee extension to target quadriceps strength should be included in ACLR rehabilitation with consideration of individual patient factors such as anterior knee pain with appropriate periodization and progression.

It should be noted that when addressing quadriceps atrophy and strength deficits, the selected exercise must create an external knee flexion moment (eKFM) sufficient to require force production demands of the quadriceps at a level that stimulates adaptation. An example of using biomechanical principles to increase quadriceps demand can be illustrated during multi-joint CKC exercises. If individuals squat with their knees moving forward past their toes the external knee flexion moment and required quadriceps force requirements will increase. However, patient tolerance to this increased eKFM must be closely monitored. For example, anterior knee symptoms may be less tolerant to increases in eKFM if a quadriceps tendon or patellar tendon graft was used during ACLR and a slower progression may be necessary.

\section{CROSS-EDUCATION}

Cross-education refers to the ability to improve strength in the contralateral limb by performing unilateral exercises. This has been achieved through various training protocols, and a recent meta-analysis suggested eccentric muscle contractions and moderate volumes of exercise to best implement cross-education. ${ }^{135}$ Following ACLR, eight weeks of cross-education in addition to standard care improved quadriceps strength $28-31 \%$ more than control participants

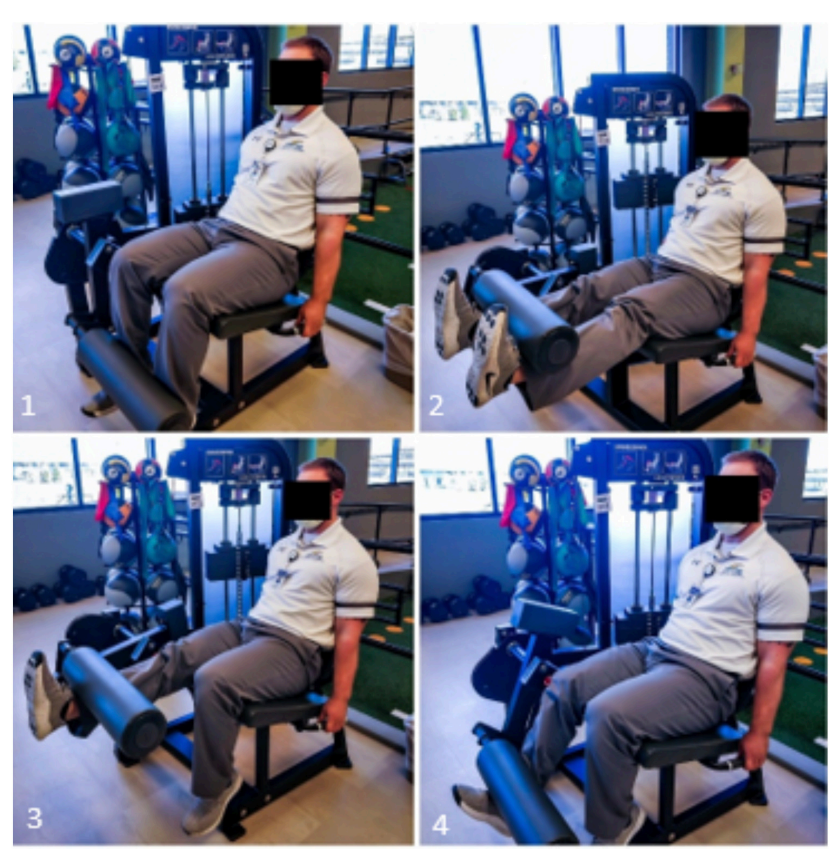

\section{Figure 1. Example of supramaximal eccentric exercise for the quadriceps.}

Complete extension concentrically with two legs $(1 \rightarrow 2)$, lower uninvolved leg keeping working limb extended (3) and then lower eccentrically with working $\operatorname{limb}(4)$.

receiving standard care. ${ }^{136}$ The benefits of cross-education can be used throughout the continuum of rehabilitation, but perhaps most effectively in the early phases when the injured limb is not able to tolerate higher intensity strength training or when comorbidities such as patellofemoral chondrosis or anterior knee pain are limiting loading of the involved knee.

\section{INTERVENTIONS FOR RATE OF FORCE DEVELOPMENT}

RFD refers to the ability of the neuromuscular system to produce force quickly following the initiation of a muscle contraction. Force application during most sporting activities such as jumping and changes of direction occurs within very short time frames, with some activities such as ground contact times while sprinting occurring in under $200 \mathrm{~ms} .{ }^{137}$ The momentum change in these activities is directly related to the impulse generated. In this context, impulse can be defined as force multiplied by time. Because there is a time constraint to these tasks, a higher RFD will allow more impulse to be generated in the same time frame and lead to better performance. ${ }^{138}$ Optimal development of RFD is dependent upon adequate development of muscle strength as maximal strength may account for 52-81\% RFD variance. ${ }^{139}$ Improving RFD and impulse is typically targeted via training at high velocities, or with intent to perform exercises and movements explosively. ${ }^{16,140}$ It should be made clear that the intention to complete a movement with a high velocity is more important than the actual movement velocity. ${ }^{141}$ This has practical implications as one may train across a loading spectrum including both high and low loads as long as the intention to move explosively is present. Common training modalities include high intensity 
strength training, Olympic weightlifting derivatives, plyometrics, accelerations, decelerations, and ballistic isometrics. The patient should be cued to "explode" or complete a repetition as fast and hard as possible to maximize the benefits of these exercises. While most interventions to improve RFD typically occur later in rehabilitation, one may begin targeting this earlier by manipulating tempos or intending to complete the concentric or eccentric portion of an exercise as quickly as possible, provided that the patient has already demonstrated proficiency in the same task in a slow and controlled manner. Even an intervention such as a quadriceps setting exercise may be utilized with an RFD emphasis by intending to complete the quad set "fast and hard.” The intensity of interventions for RFD should be increased in a gradual progressive manner to ensure the patient has adequate tissue loading capacity to tolerate increased forces.

Additionally, eccentric, concentric, and isometric muscle actions may be trained separately with examples of phasespecific exercises including drop lands, squat jumps, and isometric mid-thigh pulls, respectively. Once RFD and explosive strength are adequately developed, training may shift to place more emphasis on reactive strength. Reactive strength involves tasks utilizing the stretch-shortening cycle and uses the ability of muscles to store and utilize elastic energy to perform a concentric action in rapid succession from an eccentric action. Reactive strength is typically trained with plyometrics of progressive training intensities. During these exercises, the patient should attempt to minimize their ground contact time to promote reactive strength adaptations. It should be noted that literature has shown decreased knee flexion angles during landings following ACLR, ${ }^{88}$ so the clinicians should ensure that the patient is not adopting this strategy to offload the knee. The minimum detectable change for knee motion during landing during 2D video analysis has been reported to be 6-13 degrees, but this has not been established for visual inspection. ${ }^{142}$ When detected, it is suggested to implement task regressions to ensure proficiency prior to reimplementing the task with the observed movement impairments. Additionally, one may promote increased knee flexion during landing by incorporating strategies previously reported to facilitate motor learning such as implicit instructions and external focus of attention, ${ }^{143}$ which further emphasizes the interdependency of several physiologic systems. Reactive strength training modalities may also aid in mitigating deleterious skeletal changes discussed earlier such as reduced bone mineral density. ${ }^{44,144}$

\section{CONCLUSION}

This commentary has highlighted musculoskeletal considerations for rehabilitation following ACL injury and ACLR from a multi-physiologic systems approach. Several musculoskeletal alterations that occur after ACL injury and ACLR have been identified and serve as a foundation for guiding the rehabilitation process. Various clinically available testing methods for identifying and monitoring these deficits have been discussed, as well as interventions that integrate with other body systems to ultimately resolve movement limitations.

\section{FINANCIAL DISCLOSURES}

The authors have declared no conflict of interest.

\section{FUNDING}

None declared.

\section{ACKNOWLEDGEMENTS}

None. 


\section{REFERENCES}

1. American Physical Therapy Association. An American Physical Therapy Association white paper. Physical therapist practice and the human movement system. Published online 2015:1-4.

2. American Physical Therapy Association. Guiding Principles to Achieve the Vision. Accessed September 21, 2021. https://www.apta.org/siteassets/pdfs/policie s/guiding-principles-to-achieve-vision.pdf

3. Saladin L, Voight M. Introduction to the movement system as the foundation for physical therapist practice education and research. Int J Sports Phys Ther. 2017;12(6):858-861. doi:10.16603/ijspt2017085 $\underline{8}$

4. Hunter SJ, Norton BJ, Powers CM, Saladin LK, Delitto A. Rothstein roundtable podcast-"Putting all of our eggs in one basket: human movement system." Phys Ther. 2015;95(11):1466-1466. doi:10.2522/ptj.20 $\underline{15.95 .11 .1466}$

5. McClure P, Tevald M, Zarzycki R, et al. The 4-element movement system model to guide physical therapist education, practice, and movement-related research. Phys Ther. 2021;101(3). doi:10.1093/ptj/pza b024

6. Davids K, Glazier P, Araújo D, Bartlett R. Movement systems as dynamical systems. Sports Medicine. 2003;33(4):245-260. doi:10.2165/00007256-20033304 $\underline{0-00001}$

7. Mauro CS, Irrgang JJ, Williams BA, Harner CD. Loss of extension following anterior cruciate ligament reconstruction: analysis of incidence and etiology using IKDC criteria. Arthroscopy. 2008;24(2):146-153. doi:10.1016/j.arthro.2007.08.026

8. Robertson GA, Coleman SG, Keating JF. Knee stiffness following anterior cruciate ligament reconstruction: the incidence and associated factors of knee stiffness following anterior cruciate ligament reconstruction. Knee. 2009;16(4):245-247. doi:10.101 6/j.knee.2008.12.014

9. Cavanaugh JT, Powers M. ACL rehabilitation progression: where are we now? Curr Rev Musculoskelet Med. 2017;10(3):289-296. doi:10.1007/s $\underline{12178-017-9426-3}$

10. Eckenrode BJ, Carey JL, Sennett BJ, Zgonis MH. Prevention and management of post-operative complications following ACL reconstruction. Curr Rev Musculoskelet Med. 2017;10(3):315-321. doi:10.1007/s 12178-017-9427-2
11. Wylie JD, Marchand LS, Burks RT. Etiologic factors that lead to failure after primary anterior cruciate ligament surgery. Clin Sports Med. 2017;36(1):155-172. doi:10.1016/j.csm.2016.08.007

12. Aglietti P, Buzzi R, De Felice R, Paolini G, Zaccherotti G. Results of surgical treatment of arthrofibrosis after ACL reconstruction. Knee Surg Sports Traumatol Arthrosc. 1995;3(2):83-88. doi:10.10 $\underline{07 / b f 01552380}$

13. Novacheck TF. The biomechanics of running. Gait \& Posture. 1998;7(1):77-95. doi:10.1016/S0966-636 $\underline{2(97) 00038-6}$

14. Gheller RG, Dal Pupo J, Ache-Dias J, Detanico D, Padulo J, dos Santos SG. Effect of different knee starting angles on intersegmental coordination and performance in vertical jumps. Hum Mov Sci. 2015;42:71-80. doi:10.1016/j.humov.2015.04.010

15. Birchmeier T, Lisee C, Kane K, Brazier B, Triplett A, Kuenze C. Quadriceps muscle size following ACL injury and reconstruction: a systematic review. $J$ Orthop Res. 2020;38(3):598-608. doi:10.1002/jor.2448 $\underline{9}$

16. Maestroni L, Read P, Bishop C, Turner A. Strength and power training in rehabilitation: underpinning principles and practical strategies to return athletes to high performance. Sports Med. 2020;50(2):239-252. doi:10.1007/s40279-019-01195-6

17. Noehren B, Andersen A, Hardy P, et al. Cellular and morphological alterations in the vastus lateralis muscle as the result of ACL injury and reconstruction. J Bone Joint Surg Am. 2016;98(18):1541-1547. doi:10.2 106/jbjs.16.00035

18. Lepley LK. Deficits in quadriceps strength and patient-oriented outcomes at return to activity after ACL reconstruction: a review of the current literature. Sports Health. 2015;7(3):231-238. doi:10.1177/194173 $\underline{8115578112}$

19. Toole AR, Ithurburn MP, Rauh MJ, Hewett TE, Paterno MV, Schmitt LC. Young athletes cleared for sports participation after anterior cruciate ligament reconstruction: how many actually meet recommended return-to-sport criterion cutoffs? J Orthop Sports Phys Ther. 2017;47(11):825-833. doi:1 $\underline{0.2519 / j o s p t .2017 .7227}$ 
20. Webster KE, Feller JA. Who passes return-to-sport tests, and which tests are most strongly associated with return to play after anterior cruciate ligament reconstruction? Orthop J Sports Med.

2020;8(12):2325967120969425. doi:10.1177/23259671 20969425

21. Petersen W, Taheri P, Forkel P, Zantop T. Return to play following ACL reconstruction: a systematic review about strength deficits. Arch Orthop Trauma Surg. 2014;134(10):1417-1428. doi:10.1007/s00402-01 4-1992-X

22. Kline PW, Morgan KD, Johnson DL, Ireland ML, Noehren B. Impaired quadriceps rate of torque development and knee mechanics after anterior cruciate ligament reconstruction with patellar tendon autograft. Am J Sports Med. 2015;43(10):2553-2558. d oi:10.1177/0363546515595834

23. Knezevic OM, Mirkov DM, Kadija M, Nedeljkovic A, Jaric S. Asymmetries in explosive strength following anterior cruciate ligament reconstruction. Knee. 2014;21(6):1039-1045. doi:10.1016/j.knee.201 4.07.021

24. Turpeinen JT, Freitas TT, Rubio-Arias JÁ, Jordan MJ, Aagaard P. Contractile rate of force development after anterior cruciate ligament reconstruction-a comprehensive review and meta-analysis. Scand $J$ Med Sci Sports. 2020;30(9):1572-1585. doi:10.1111/sm $\underline{\mathrm{s} .13733}$

25. Lloyd RS, Oliver JL, Kember LS, Myer GD, Read PJ. Individual hop analysis and reactive strength ratios provide better discrimination of ACL reconstructed limb deficits than triple hop for distance scores in athletes returning to sport. Knee. 2020;27(5):1357-1364. doi:10.1016/j.knee.2020.07.00 $\underline{3}$

26. Read PJ, Davies WT, Bishop C, Mc Auliffe S, Wilson MG, Turner AN. Residual deficits in reactive strength indicate incomplete restoration of athletic qualities following anterior cruciate ligament reconstruction in professional soccer players. J Athl Train. Published online 2020. doi:10.4085/169-20

27. Lee DW, Yang SJ, Cho SI, Lee JH, Kim JG. Singleleg vertical jump test as a functional test after anterior cruciate ligament reconstruction. Knee. 2018;25(6):1016-1026. doi:10.1016/j.knee.2018.07.01 $\underline{4}$

28. O’Malley E, Richter C, King E, et al. Countermovement jump and isokinetic dynamometry as measures of rehabilitation status after anterior cruciate ligament reconstruction. J Athl Train. 2018;53(7):687-695. doi:10.4085/1062-6050-480-16
29. Pratt KA, Sigward SM. Detection of knee power deficits following anterior cruciate ligament reconstruction using wearable sensors. J Orthop Sports Phys Ther. 2018;48(11):895-902. doi:10.2519/jo spt.2018.7995

30. Chung KS, Ha JK, Yeom $\mathrm{CH}$, et al. Are muscle strength and function of the uninjured lower limb weakened after anterior cruciate ligament injury? Two-year follow-up after reconstruction. Am J Sports Med. 2015;43(12):3013-3021. doi:10.1177/036354651 $\underline{5606126}$

31. Mirkov DM, Knezevic OM, Maffiuletti NA, Kadija M, Nedeljkovic A, Jaric S. Contralateral limb deficit after ACL-reconstruction: an analysis of early and late phase of rate of force development. J Sports Sci. 2017;35(5):435-440. doi:10.1080/02640414.2016.1168 $\underline{933}$

32. Rice DA, McNair PJ. Quadriceps arthrogenic muscle inhibition: neural mechanisms and treatment perspectives. Semin Arthritis Rheum. 2010;40(3):250-266. doi:10.1016/j.semarthrit.2009.1 $\underline{0.001}$

33. Hart JM, Pietrosimone B, Hertel J, Ingersoll CD. Quadriceps activation following knee injuries: a systematic review. J Athl Train. 2010;45(1):87-97. do $\mathrm{i}: 10.4085 / 1062-6050-45.1 .87$

34. Harkey MS, Luc-Harkey BA, Lepley AS, et al. Persistent muscle inhibition after anterior cruciate ligament reconstruction: role of reflex excitability. Med Sci Sports Exerc. 2016;48(12):2370-2377. doi:10.1 249/mss.0000000000001046

35. Arhos EK, Thoma LM, Grindem H, Logerstedt D, Risberg MA, Snyder-Mackler L. Association of quadriceps strength symmetry and surgical status with clinical osteoarthritis 5 years after anterior cruciate ligament rupture. Arthritis Care Res. Published online 2020. doi:10.1002/acr.24479

36. Grindem H, Snyder-Mackler L, Moksnes H, Engebretsen L, Risberg MA. Simple decision rules can reduce reinjury risk by $84 \%$ after ACL reconstruction: the Delaware-Oslo ACL cohort study. Br J Sports Med. 2016;50(13):804-808. doi:10.1136/bjsports-2016-0960 $\underline{31}$

37. Norte GE, Hertel J, Saliba SA, Diduch DR, Hart JM. Quadriceps function and patient-reported outcomes after anterior cruciate ligament reconstruction in patients with or without knee osteoarthritis. J Athl Train. 2018;53(10):965-975. doi:10.4085/1062-6050-1 70-17 
38. Rice DA, McNair PJ, Lewis GN, Dalbeth N. Quadriceps arthrogenic muscle inhibition: the effects of experimental knee joint effusion on motor cortex excitability. Arthritis Res Ther. 2014;16(6):502. doi:1 0.1186/s13075-014-0502-4

39. Grooms DR, Page SJ, Nichols-Larsen DS, Chaudhari AM, White SE, Onate JA. Neuroplasticity associated with anterior cruciate ligament reconstruction. J Orthop Sports Phys Ther. 2017;47(3):180-189. doi:10.2519/jospt.2017.7003

40. Lynch AD, Logerstedt DS, Axe MJ, Snyder-Mackler L. Quadriceps activation failure after anterior cruciate ligament rupture is not mediated by knee joint effusion. J Orthop Sports Phys Ther. 2012;42(6):502-510. doi:10.2519/jospt.2012.3793

41. Alentorn-Geli E, Gotecha D, Steinbacher G, et al. The presence of patellar tendinopathy in the bonepatellar tendon-bone autograft may increase the risk of anterior cruciate ligament graft failure. Knee Surg Sports Traumatol Arthrosc. 2019;27(3):766-772. doi:1 0.1007/s00167-018-5066-4

42. Lee GH, McCulloch P, Cole BJ, Bush-Joseph CA, Bach BR Jr. The incidence of acute patellar tendon harvest complications for anterior cruciate ligament reconstruction. Arthroscopy. 2008;24(2):162-166. do i:10.1016/j.arthro.2007.08.020

43. Reiman MP, Rogers ME, Manske RC. Interlimb differences in lower extremity bone mineral density following anterior cruciate ligament reconstruction. $J$ Orthop Sports Phys Ther. 2006;36(11):837-844. doi:1 $\underline{0.2519 / j o s p t .2006 .2278}$

44. Nyland J, Fisher B, Brand E, Krupp R, Caborn DN. Osseous deficits after anterior cruciate ligament injury and reconstruction: a systematic literature review with suggestions to improve osseous homeostasis. Arthroscopy. 2010;26(9):1248-1257. do i:10.1016/j.arthro.2010.03.017

45. van Meer BL, Waarsing JH, van Eijsden WA, et al. Bone mineral density changes in the knee following anterior cruciate ligament rupture. Osteoarthritis Cartilage. 2014;22(1):154-161. doi:10.1016/j.joca.201 $\underline{3.11 .005}$

46. Frobell RB. Change in cartilage thickness, posttraumatic bone marrow lesions, and joint fluid volumes after acute ACL disruption: a two-year prospective MRI study of sixty-one subjects. J Bone Joint Surg Am. 2011;93(12):1096-1103. doi:10.2106/jbj s.J.00929

47. Van Ginckel A, Verdonk P, Victor J, Witvrouw E. Cartilage status in relation to return to sports after anterior cruciate ligament reconstruction. Am J Sports Med. 2013;41(3):550-559. doi:10.1177/036354651247 $\underline{3568}$
48. Van Ginckel A, Verdonk P, Witvrouw E. Cartilage adaptation after anterior cruciate ligament injury and reconstruction: implications for clinical management and research? A systematic review of longitudinal MRI studies. Osteoarthritis Cartilage. 2013;21(8):1009-1024. doi:10.1016/j.joca.2013.04.015

49. Ithurburn MP, Zbojniewicz AM, Thomas S, et al. Lower patient-reported function at 2 years is associated with elevated knee cartilage T1rho and T2 relaxation times at 5 years in young athletes after ACL reconstruction. Knee Surg Sports Traumatol Arthrosc. 2019;27(8):2643-2652. doi:10.1007/s0016 7-018-5291-X

50. Kumar D, Su F, Wu D, et al. Frontal plane knee mechanics and early cartilage degeneration in people with anterior cruciate ligament reconstruction: a longitudinal study. Am J Sports Med. 2018;46(2):378-387. doi:10.1177/0363546517739605

51. Li X, Kuo D, Theologis A, et al. Cartilage in anterior cruciate ligament-reconstructed knees: MR imaging $\mathrm{T} 1\{\mathrm{rho}\}$ and $\mathrm{T} 2$--initial experience with 1-year follow-up. Radiology. 2011;258(2):505-514. do i:10.1148/radiol.10101006

52. Klocke NF, Amendola A, Thedens DR, et al. Comparison of T1 $\rho$, dGEMRIC, and quantitative T2 MRI in preoperative ACL rupture patients. Acad Radiol. 2013;20(1):99-107. doi:10.1016/j.acra.2012.0 $\underline{7.009}$

53. Shimizu T, Markes AR, Samaan MA, et al. Patients with abnormal limb kinetics at 6 months after anterior cruciate ligament reconstruction have an increased risk of persistent medial meniscal abnormality at 3 years. Orthop J Sports Med. 2020;8(1):2325967119895248. doi:10.1177/232596711 $\underline{9895248}$

54. Friel NA, Chu CR. The role of ACL injury in the development of posttraumatic knee osteoarthritis. Clin Sports Med. 2013;32(1):1-12. doi:10.1016/i.csm.2 $\underline{012.08 .017}$

55. Nishimori M, Deie M, Adachi N, et al. Articular cartilage injury of the posterior lateral tibial plateau associated with acute anterior cruciate ligament injury. Knee Surg Sports Traumatol Arthrosc. 2008;16(3):270-274. doi:10.1007/s00167-007-0458-x

56. Johnson DL, Urban WP Jr, Caborn DN, Vanarthos WJ, Carlson CS. Articular cartilage changes seen with magnetic resonance imaging-detected bone bruises associated with acute anterior cruciate ligament rupture. Am J Sports Med. 1998;26(3):409-414. doi:1 $\underline{0.1177 / 03635465980260031101}$ 
57. Øiestad BE, Engebretsen L, Storheim K, Risberg MA. Knee osteoarthritis after anterior cruciate ligament injury: a systematic review. Am J Sports Med. 2009;37(7):1434-1443. doi:10.1177/036354650933882 $\underline{7}$

58. Wellsandt E, Failla MJ, Snyder-Mackler L. Limb symmetry indexes can overestimate knee function after anterior cruciate ligament injury. J Orthop Sports Phys Ther. 2017;47(5):334-338. doi:10.2519/jospt.201 $\underline{7.7285}$

59. Kirwan JR, Byron MA, Winfield J, Altman DG, Gumpel JM. Circumferential measurements in the assessment of synovitis of the knee. Rheumatol Rehabil. 1979;18(2):78-84. doi:10.1093/rheumatolog $\mathrm{y} / 18.2 .78$

60. Sturgill LP, Snyder-Mackler L, Manal TJ, Axe MJ. Interrater reliability of a clinical scale to assess knee joint effusion. J Orthop Sports Phys Ther. 2009;39(12):845-849. doi:10.2519/jospt.2009.3143

61. Adams D, Logerstedt DS, Hunter-Giordano A, Axe MJ, Snyder-Mackler L. Current concepts for anterior cruciate ligament reconstruction: a criterion-based rehabilitation progression. J Orthop Sports Phys Ther. 2012;42(7):601-614. doi:10.2519/jospt.2012.3871

62. Shelbourne KD, Gray T. Minimum 10-year results after anterior cruciate ligament reconstruction: how the loss of normal knee motion compounds other factors related to the development of osteoarthritis after surgery. Am J Sports Med. 2009;37(3):471-480. d oi: $10.1177 / 0363546508326709$

63. Laupattarakasem W, Paholpak P, Kosuwon W. The relevant level to estimate girth difference between thighs after anterior cruciate ligament deficiency. $J$ Med Assoc Thai. 2012;95:S178-S183.

64. Arangio GA, Chen C, Kalady M, Reed JF III. Thigh muscle size and strength after anterior cruciate ligament reconstruction and rehabilitation. J Orthop Sports Phys Ther. 1997;26(5):238-243. doi:10.2519/jos pt.1997.26.5.238

65. Suchomel TJ, Nimphius S, Stone MH. The importance of muscular strength in athletic performance. Sports Med. 2016;46(10):1419-1449. do $\mathrm{i}: 10.1007 / \mathrm{s} 40279-016-0486-0$

66. Pietrosimone B, Lepley AS, Harkey MS, et al. Quadriceps strength predicts self-reported function post-ACL reconstruction. Med Sci Sports Exerc. 2016;48(9):1671-1677. doi:10.1249/MSS.00000000000 $\underline{00946}$
67. Kuenze C, Hertel J, Saliba S, Diduch DR, Weltman A, Hart JM. Clinical thresholds for quadriceps assessment after anterior cruciate ligament reconstruction. J Sport Rehabil. 2015;24(1):36-46. do i:10.1123/jsr.2013-0110

68. Bohannon RW. Considerations and practical options for measuring muscle strength: a narrative review. Biomed Res Int. 2019;2019:8194537. doi:10.11 $\underline{55 / 2019 / 8194537}$

69. Haff GG, Triplett NT, eds. Essentials of Strength Training and Conditioning: National Strength and Conditioning Association. 4th ed. Human Kinetics; 2016.

70. Sinacore JA, Evans AM, Lynch BN, Joreitz RE, Irrgang JJ, Lynch AD. Diagnostic accuracy of handheld dynamometry and 1-repetition-maximum tests for identifying meaningful quadriceps strength asymmetries. J Orthop Sports Phys Ther. 2017;47(2):97-107. doi:10.2519/jospt.2017.6651

71. Almangoush A, Herrington L, Jones R. A preliminary reliability study of a qualitative scoring system of limb alignment during single leg squat. Phys Ther Rehab. Published online 2014:1-7. doi:10.72 43/2055-2386-1-2

72. Herrington L, Munro A. A preliminary investigation to establish the criterion validity of a qualitative scoring system of limb alignment during single leg squat and landing. J Exerc Sports Orthop. 2014;1(2):1-6.

73. Hall MP, Paik RS, Ware AJ, Mohr KJ, Limpisvasti O. Neuromuscular evaluation with single-leg squat test at 6 months after anterior cruciate ligament reconstruction. Orthop J Sports Med. 2015;3(3):2325967115575900. doi:10.1177/232596711 $\underline{5575900}$

74. Batty LM, Feller JA, Hartwig T, Devitt BM, Webster KE. Single-leg squat performance and its relationship to extensor mechanism strength after anterior cruciate ligament reconstruction. Am J Sports Med. 2019;47(14):3423-3428. doi:10.1177/03635465198784 $\underline{32}$

75. Herrington L, Myer G, Horsley I. Task based rehabilitation protocol for elite athletes following Anterior Cruciate ligament reconstruction: a clinical commentary. Phys Ther Sport. 2013;14(4):188-198. do i:10.1016/j.ptsp.2013.08.001

76. Rodríguez-Rosell D, Pareja-Blanco F, Aagaard P, González-Badillo JJ. Physiological and methodological aspects of rate of force development assessment in human skeletal muscle. Clin Physiol Funct Imaging. 2018;38(5):743-762. doi:10.1111/cpf.1 $\underline{2495}$ 
77. Maffiuletti NA, Aagaard P, Blazevich AJ, Folland J, Tillin N, Duchateau J. Rate of force development: physiological and methodological considerations. Eur J Appl Physiol. 2016;116(6):1091-1116. doi:10.1007/s0 0421-016-3346-6

78. Cobian DG, Koch CM, Amendola A, Williams GN. Knee extensor rate of torque development before and after arthroscopic partial meniscectomy, with analysis of neuromuscular mechanisms. J Orthop Sports Phys Ther. 2017;47(12):945-956. doi:10.2519/jospt.2017.73 $\underline{10}$

79. Lesnak J, Anderson D, Farmer B, Katsavelis D, Grindstaff TL. Validity of hand-held dynamometry in measuring quadriceps strength and rate of torque development. Int J Sports Phys Ther. 2019;14(2):180-187. doi:10.26603/ijspt20190180

80. Suchomel TJ, Bailey CA, Sole CJ, Grazer JL, Beckham GK. Using reactive strength index-modified as an explosive performance measurement tool in Division I athletes. J Strength Cond Res. 2015;29(4):899-904. doi:10.1519/jsc.00000000000007 $\underline{43}$

81. Flanagan EP, Comyns TM. The use of contact time and the reactive strength index to optimize fast stretch-shortening cycle training. Strength Cond J. 2008;30(5):32-38. doi:10.1519/SSC.0b013e318187e25 $\underline{\mathrm{b}}$

82. Haynes T, Bishop C, Antrobus M, Brazier J. The validity and reliability of the My Jump 2 app for measuring the reactive strength index and drop jump performance. J Sports Med Phys Fitness. 2019;59(2):253-258. doi:10.23736/s0022-4707.18.081 95-1

83. Gustavsson A, Neeter C, Thomee P, et al. A test battery for evaluating hop performance in patients with an ACL injury and patients who have undergone ACL reconstruction. Knee Surg Sports Traumatol Arthrosc. 2006;14(8):778-788. doi:10.1007/s00167-00 $\underline{\text { 6-0045-6 }}$

84. Noyes FR, Barber SD, Mangine RE. Abnormal lower limb symmetry determined by function hop tests after anterior cruciate ligament rupture. Am J Sports Med. 1991;19(5):513-518. doi:10.1177/0363546 59101900518

85. Reid A, Birmingham TB, Stratford PW, Alcock GK, Giffin JR. Hop testing provides a reliable and valid outcome measure during rehabilitation after anterior cruciate ligament reconstruction. Phys Ther.

2007;87(3):337-349. doi:10.2522/ptj.20060143
86. Davies WT, Myer GD, Read PJ. Is it time we better understood the tests we are using for return to sport decision making following ACL reconstruction? A critical review of the hop tests. Sports Med. 2020;50(3):485-495. doi:10.1007/s40279-019-01221-7

87. Welling W, Benjaminse A, Seil R, Lemmink K, Gokeler A. Altered movement during single leg hop test after ACL reconstruction: implications to incorporate 2-D video movement analysis for hop tests. Knee Surg Sports Traumatol Arthrosc. 2018;26(10):3012-3019. doi:10.1007/s00167-018-489 $\underline{3-7}$

88. Kotsifaki A, Korakakis V, Whiteley R, Van Rossom $\mathrm{S}$, Jonkers I. Measuring only hop distance during single leg hop testing is insufficient to detect deficits in knee function after ACL reconstruction: a systematic review and meta-analysis. Br J Sports Med. 2020;54(3):139-153. doi:10.1136/bjsports-2018-09991 $\underline{8}$

89. Burgi CR, Peters S, Ardern CL, et al. Which criteria are used to clear patients to return to sport after primary ACL reconstruction? A scoping review. $\mathrm{Br} J$ Sports Med. 2019;53(18):1154-1161. doi:10.1136/bjsp orts-2018-099982

90. Palmieri-Smith RM, Lepley LK. Quadriceps strength asymmetry after anterior cruciate ligament reconstruction alters knee joint biomechanics and functional performance at time of return to activity. Am J Sports Med. 2015;43(7):1662-1669. doi:10.1177/0 363546515578252

91. Snyder-Mackler L, Delitto A, Bailey SL, Stralka SW. Strength of the quadriceps femoris muscle and functional recovery after reconstruction of the anterior cruciate ligament. A prospective, randomized clinical trial of electrical stimulation. $J$ Bone Joint Surg Am. 1995;77(8):1166-1173. doi:10.210 6/00004623-199508000-00004

92. Culvenor AG, Ruhdorfer A, Juhl C, Eckstein F, Øiestad BE. Knee extensor strength and risk of structural, symptomatic, and functional decline in knee osteoarthritis: a systematic review and metaanalysis. Arthritis Care Res. 2017;69(5):649-658. doi:1 $\underline{0.1002 / \text { acr.23005 }}$

93. American College of Sports Medicine. American College of Sports Medicine position stand.

Progression models in resistance training for healthy adults. Med Sci Sports Exerc. 2009;41(3):687-708. do $\mathrm{i}: 10.1249 / \mathrm{MSS} .0 \mathrm{~b} 013 \mathrm{e} 3181915670$

94. McHugh MP, Tyler TF, Gleim GW, Nicholas SJ. Preoperative indicators of motion loss and weakness following anterior cruciate ligament reconstruction. $J$ Orthop Sports Phys Ther. 1998;27(6):407-411. doi:10.2 519/jospt.1998.27.6.407 
95. Delaloye JR, Murar J, Vieira TD, et al. Knee extension deficit in the early postoperative period predisposes to cyclops syndrome after anterior cruciate ligament reconstruction: a risk factor analysis in 3633 patients from the SANTI study group database. Am J Sports Med. 2020;48(3):565-572. doi:1 $0.1177 / 0363546519897064$

96. Son D, Harijan A. Overview of surgical scar prevention and management. J Korean Med Sci. 2014;29(6):751-757. doi:10.3346/jkms.2014.29.6.751

97. DeSantana JM, Walsh DM, Vance C, Rakel BA, Sluka KA. Effectiveness of transcutaneous electrical nerve stimulation for treatment of hyperalgesia and pain. Curr Rheumatol Rep. 2008;10(6):492-499. doi:1 $\underline{0.1007 / \mathrm{s} 11926-008-0080-\mathrm{z}}$

98. Raynor MC, Pietrobon R, Guller U, Higgins LD. Cryotherapy after ACL reconstruction: a metaanalysis. J Knee Surg. 2005;18(2):123-129. doi:10.105 5/s-0030-1248169

99. Sari Z, Aydoğdu O, Demirbüken İ, Yurdalan SU, Polat MG. A better way to decrease knee swelling in patients with knee osteoarthritis: a single-blind randomised controlled trial. Pain Res Manag. 2019;2019:8514808-8514808. doi:10.1155/2019/8514 $\underline{808}$

100. Ahmad CS, Kwak SD, Ateshian GA, Warden WH, Steadman JR, Mow VC. Effects of patellar tendon adhesion to the anterior tibia on knee mechanics. Am J Sports Med. 1998;26(5):715-724.

101. McClure PW, Blackburn LG, Dusold C. The use of splints in the treatment of joint stiffness: biologic rationale and an algorithm for making clinical decisions. Phys Ther. 1994;74(12):1101-1107. doi:10.1 093/ptj/74.12.1101

102. Kambhampati SBS, Gollamudi S, Shanmugasundaram S, Josyula VVS. Cyclops lesions of the knee: a narrative review of the literature. Orthop J Sports Med. 2020;8(8):2325967120945671-2325967120945671. do i:10.1177/2325967120945671

103. Rhea MR, Alderman BL. A meta-analysis of periodized versus nonperiodized strength and power training programs. Res Q Exerc Sport. 2004;75(4):413-422. doi:10.1080/02701367.2004.1060 9174

104. Harries SK, Lubans DR, Callister R. Systematic review and meta-analysis of linear and undulating periodized resistance training programs on muscular strength. J Strength Cond Res. 2015;29(4):1113-1125. doi:10.1519/isc.0000000000000712
105. Lorenz D, Morrison S. Current concepts in periodization of strength and conditioning for the sports physical therapist. Int J Sports Phys Ther. 2015;10(6):734-747.

106. Panariello RA, Stump TJ, Maddalone D. Postoperative rehabilitation and return to play after anterior cruciate ligament reconstruction. Oper Tech Sports Med. 2016;24(1):35-44. doi:10.1053/j.otsm.201 $\underline{5.09 .007}$

107. Fitzgerald GK, Piva SR, Irrgang JJ. A modified neuromuscular electrical stimulation protocol for quadriceps strength training following anterior cruciate ligament reconstruction. J Orthop Sports Phys Ther. 2003;33(9):492-501. doi:10.2519/jospt.2003.3 $\underline{3.9 .492}$

108. Hauger AV, Reiman MP, Bjordal JM, Sheets C, Ledbetter L, Goode AP. Neuromuscular electrical stimulation is effective in strengthening the quadriceps muscle after anterior cruciate ligament surgery. Knee Surg Sports Traumatol Arthrosc. 2018;26(2):399-410. doi:10.1007/s00167-017-4669-5

109. Lepley LK, Wojtys EM, Palmieri-Smith RM. Combination of eccentric exercise and neuromuscular electrical stimulation to improve quadriceps function post-ACL reconstruction. Knee. 2015;22(3):270-277. d oi:10.1016/j.knee.2014.11.013

110. Pietrosimone BG, Ingersoll CD. Focal knee joint cooling increases the quadriceps central activation ratio. J Sports Sci. 2009;27(8):873-879. doi:10.1080/02 640410902929374

111. Pietrosimone BG, Hart JM, Saliba SA, Hertel J, Ingersoll CD. Immediate effects of transcutaneous electrical nerve stimulation and focal knee joint cooling on quadriceps activation. Med Sci Sports Exerc. 2009;41(6):1175-1181. doi:10.1249/MSS.0b013 e3181982557

112. Hoch JM, Perkins WO, Hartman JR, Hoch MC. Somatosensory deficits in post-ACL reconstruction patients: A case-control study. Muscle Nerve. 2017;55(1):5-8. doi:10.1002/mus.25167

113. Lebonvallet N, Laverdet B, Misery L, Desmoulière A, Girard D. New insights into the roles of myofibroblasts and innervation during skin healing and innovative therapies to improve scar innervation. Exp Dermatol. 2018;27(9):950-958. doi:10.1111/exd.1 $\underline{3681}$

114. Cormie P, McGuigan MR, Newton RU. Adaptations in athletic performance after ballistic power versus strength training. Med Sci Sports Exerc. 2010;42(8):1582-1598. doi:10.1249/MSS.0b013e3181d 2013a 
115. Haff GG, Nimphius S. Training principles for power. Strength Cond J. 2012;34(6):2-12. doi:10.1519/ $\underline{\text { SSC.0b013e31826db467 }}$

116. Schoenfeld BJ. The mechanisms of muscle hypertrophy and their application to resistance training. J Strength Cond Res. 2010;24(10):2857-2872. doi:10.1519/ISC.0b013e3181e840f3

117. Cormie P, McGuigan MR, Newton RU. Developing maximal neuromuscular power: Part 1--biological basis of maximal power production. Sports Med. 2011;41(1):17-38. doi:10.2165/11537690-00000000 $\underline{0-00000}$

118. Lepley LK, Davi SM, Burland JP, Lepley AS. Muscle atrophy after ACL injury: implications for clinical practice. Sports Health. 2020;12(6):579-586. $\underline{\mathrm{d}}$ oi:10.1177/1941738120944256

119. Rodriguez KM, Palmieri-Smith RM, Krishnan C. How does anterior cruciate ligament reconstruction affect the functioning of the brain and spinal cord? A systematic review with meta-analysis. J Sport Health Sci. 2021;10(2):172-181. doi:10.1016/j.jshs.2020.07.00 $\underline{5}$

120. Zarzycki R, Morton S, Charalambous C, Pietrosimone B, Williams G, Snyder-Mackler L. Examination of corticospinal and spinal-reflexive excitability during the course of post-operative rehabilitation after ACL reconstruction. J Orthop Sports Phys Ther. Published online 2020.

121. Schoenfeld BJ. Potential mechanisms for a role of metabolic stress in hypertrophic adaptations to resistance training. Sports Med. 2013;43(3):179-194. $\underline{\mathrm{d}}$ oi:10.1007/s40279-013-0017-1

122. Schoenfeld BJ, Ogborn D, Krieger JW. Doseresponse relationship between weekly resistance training volume and increases in muscle mass: A systematic review and meta-analysis. J Sports Sci. 2017;35(11):1073-1082. doi:10.1080/02640414.2016.1 $\underline{210197}$

123. Fees M, Decker T, Snyder-Mackler L, Axe MJ. Upper extremity weight-training modifications for the injured athlete. A clinical perspective. Am J Sports Med. 1998;26(5):732-742. doi:10.1177/036354659802 60052301

124. Buckthorpe M, La Rosa G, Villa FD. Restoring knee extensor strength after anterior cruciate ligament reconstruction: a clinical commentary. Int J Sports Phys Ther. 2019;14(1):159-172.

125. Slysz J, Stultz J, Burr JF. The efficacy of blood flow restricted exercise: A systematic review \& metaanalysis. J Sci Med Sport. 2016;19(8):669-675. doi:10.1 016/j.jsams.2015.09.005
126. Patterson SD, Hughes L, Warmington S, et al. Blood flow restriction exercise: considerations of methodology, application, and safety. Front Physiol. 2019;10(533). doi:10.3389/fphys.2019.00533

127. Lorenz D, Bailey L, Wilk K, et al. Current clinical concepts: blood flow restriction training. J Athl Train. Published online 2021. doi:10.4085/418-20

128. Oranchuk DJ, Storey AG, Nelson AR, Cronin JB. Isometric training and long-term adaptations: Effects of muscle length, intensity, and intent: A systematic review. Scand J Med Sci Sports. 2019;29(4):484-503. do $\underline{\mathrm{i}: 10.1111 / \mathrm{sms} .13375}$

129. Farthing JP, Chilibeck PD. The effects of eccentric and concentric training at different velocities on muscle hypertrophy. Eur J Appl Physiol. 2003;89(6):578-586. doi:10.1007/s00421-003-0842-2

130. Higbie EJ, Cureton KJ, Warren GL III, Prior BM. Effects of concentric and eccentric training on muscle strength, cross-sectional area, and neural activation. J Appl Physiol. 1996;81(5):2173-2181. doi:10.1152/jap pl.1996.81.5.2173

131. Nishikawa K. Eccentric contraction: unraveling mechanisms of force enhancement and energy conservation. J Exp Biol. 2016;219(Pt 2):189-196. do i:10.1242/jeb.124057

132. Mikkelsen C, Werner S, Eriksson E. Closed kinetic chain alone compared to combined open and closed kinetic chain exercises for quadriceps strengthening after anterior cruciate ligament reconstruction with respect to return to sports: a prospective matched follow-up study. Knee Surg Sports Traumatol Arthrosc. 2000;8(6):337-342. doi:1 $\underline{0.1007 / \mathrm{s} 001670000143}$

133. Steinkamp LA, Dillingham MF, Markel MD, Hill JA, Kaufman KR. Biomechanical considerations in patellofemoral joint rehabilitation. Am J Sports Med. 1993;21(3):438-444. doi:10.1177/03635465930210031 $\underline{9}$

134. Noehren B, Snyder-Mackler L. Who's afraid of the big bad wolf? Open-chain exercises after anterior cruciate ligament reconstruction. J Orthop Sports Phys Ther. 2020;50(9):473-475. doi:10.2519/jospt.2020.060 9

135. Cirer-Sastre R, Beltrán-Garrido JV, Corbi F. Contralateral effects after unilateral strength training: a meta-analysis comparing training loads. J Sports Sci Med. 2017;16(2):180-186. 
136. Harput G, Ulusoy B, Yildiz TI, et al. Crosseducation improves quadriceps strength recovery after ACL reconstruction: a randomized controlled trial. Knee Surg Sports Traumatol Arthrosc. 2019;27(1):68-75. doi:10.1007/s00167-018-5040-1

137. Taber C, Bellon C, Abbott H, Bingham GE. Roles of maximal strength and rate of force development in maximizing muscular power. Strength Cond J. 2016;38(1):71-78. doi:10.1519/ssc.0000000000000193

138. Knudson DV. Correcting the use of the term "power" in the strength and conditioning literature. J Strength Cond Res. 2009;23(6):1902-1908. doi:10.151 9/ISC.0b013e3181b7f5e5

139. Andersen LL, Aagaard P. Influence of maximal muscle strength and intrinsic muscle contractile properties on contractile rate of force development. Eur J Appl Physiol. 2006;96(1):46-52. doi:10.1007/s004 21-005-0070-z

140. Turner AN, Comfort P, McMahon J, et al. Developing powerful athletes part 2: practical applications. Strength Cond J. 2021;43(1):23-31. doi:1 $\underline{0.1519 / \text { ssc. } 0000000000000544}$
141. Behm DG, Sale DG. Intended rather than actual movement velocity determines velocity-specific training response. J Appl Physiol. 1993;74(1):359-368. doi:10.1152/jappl.1993.74.1.359

142. Howe LP, Bampouras T, North J, Waldron M. Reliability of two-dimensional measures associated with bilateral drop-landing performance. Mov Sport Sci. 2020;108:39-47.

143. Gokeler A, Neuhaus D, Benjaminse A, Grooms DR, Baumeister J. Principles of motor learning to support neuroplasticity after ACL injury: implications for optimizing performance and reducing risk of second ACL injury. Sports Med. 2019;49(6):853-865. d oi:10.1007/s40279-019-01058-0

144. Watson SL, Weeks BK, Weis LJ, Harding AT, Horan SA, Beck BR. High-intensity resistance and impact training improves bone mineral density and physical function in postmenopausal women with osteopenia and osteoporosis: the LIFTMOR randomized controlled trial. J Bone Miner Res. 2018;33(2):211-220. doi:10.1002/jbmr.3284 


\section{SUPPLEMENTARY MATERIALS}

\section{Appendix A. Normative values of strength for each Level 1 cutting sport}

Download: https://ijspt.scholasticahq.com/article/29456-a-multi-systems-approach-to-human-movement-after-aclreconstruction-the-musculoskeletal-system/attachment/73676.xlsx

\section{Appendix B. Normative values of performance for each level 1 cutting sport}

Download: https://ijspt.scholasticahq.com/article/29456-a-multi-systems-approach-to-human-movement-after-aclreconstruction-the-musculoskeletal-system/attachment/74192.xlsx 